\title{
As potencialidades do mirtilo (Vaccinium Myrtillus) sob as óticas do Slow Food e do Slow Fashion
}

The capabilities of blueberry (Vaccinium Myrtillus) under the perspectives of

Slow Food and Slow Fashion

\section{Andréia Mesacasa}

Instituto Federal de Educação, Ciência e Tecnologia do Rio Grande do Sul

andreiamesacasa@hotmail.com

\section{Carla Natacha Szabat}

Instituto Federal de Educação, Ciência e Tecnologia do Rio Grande do Sul

carla_natacha_szabat@hotmail.com $\mathbf{x}$

PROJËTICA

\section{COMO CITAR ESTE ARTIGO:}

MESACASA, Andréia; SZABAT, Carla Natacha. As potencialidades do mirtilo (Vaccinium Myrtillus) sob as óticas do Slow Food e do Slow Fashion. Projética, Londrina, v. 12, n. 2, p. 317-347, 2021.

DOI: 10.5433/2236-2207.2021v12n2p317

Submissão: 09-06-2020

Aceite: $24-02-2020$ 
RESUMO: Este estudo tem como objetivo apresentar os movimentos slow food e slow fashion, evidenciando as potencialidades da utilização do mirtilo (Vaccinium Myrtillus) como elemento integrador entre os movimentos citados rumo à valorização do turismo regional. Para tanto, foi realizada uma pesquisa experimental acerca do uso do mirtilo em tingimentos artesanais. Além disso, foi utilizado como instrumento de coleta de dados uma entrevista, realizada com um dos sócios do Empório do Mirtilo, empresa localizada no município de Itá (Santa Catarina) que trabalha com o sistema colhe e pague da referida fruta. Foram realizados dois experimentos, um com as cascas do mirtilo, outro com as frutas em decomposição.Com base nos experimentos desenvolvidos, conclui-se que os resultados alcançados foram satisfatórios, evidenciando a possibilidade de utilização da matéria-prima mirtilo neste processo.

Palavras-chave: Mirtilo. Tingimento. Slow food. Slow fashion.

ABSTRACT: This research aims to present the slow food and slow fashion movements, showing the capabilities of blueberry (Vaccinium Myrtillus) as an integrating element among them, and towards the appreciation of regional tourism. To do so, an experimental research was carried out on the use of blueberry in handmade dyeing. In addition, an interview was used as instrument of data collection, conducted with one of the partners of Empório do Mirtilo, a company located in the city of Itá (Santa Catarina, Brazil) that works with a Pick and Pay system of the referred fruit. Two experiments were carried out, one with the blueberry peels, and the other with decomposing fruits. Based on the experiments, it is concluded that the results achieved were satisfactory, showing the possibility of using blueberry as raw material in this process.

Keywords: Blueberry. Dyeing. Slow food. Slow fashion. 


\section{INTRODUÇÃO}

O planeta passou por algumas transformações no decorrer dos últimos anos devido ao aumento populacional relacionado a atividades desenvolvidas, causando escassez de recursos básicos e essenciais, como a água, alterações no ciclo da natureza, extremas mudanças climáticas e a ocupação e utilização do solo de forma indevida. Por conta disso, iniciaram-se discussões acerca do futuro do planeta em relação aos níveis de consumo dos recursos finitos e sua possível exaustão (SANTOS, 2018).

A partir dessas discussões que tiveram início na década de 1970, surgiu o conceito de sustentabilidade ${ }^{1}$ que se alinha ao princípio de acúmulo de produtos apenas para a suficiência e manutenção, isto é, a obtenção somente do que será necessário para a felicidade e o bem-estar (SANTOS, 2018).

Nesse sentido, devido à escassez de recursos, uma das alternativas para produtores e consumidores, visando a proteção do meio ambiente, reside na adoção de formas de consumo mais lentas e produtos com ciclo de vida mais longos. Esse movimento, caracterizado como slow, está relacionado tanto à área da alimentação quanto à área da moda, caracterizando-se como slow food e slow fashion.

[1] $\quad$ o termo sustentabilidade teve origem da expressão "desenvolvimento sustentável" o qual foi utilizado pela primeira vez em 1987, no Relátorio Brundtland, documento de caráter socioeconômico elaborado para a Organização das Nações Unidas, termo esse que era definido como o desenvolvimento que satisfaz as necessidades do presente sem comprometer a satisfação das necessidades das gerações futuras (SALCEDO, 2014). 
O movimento slow, simbolizado pelo lento, apresenta uma maneira de pensar diferente, que se aplica a diversas áreas. O primeiro setor a aderir a essa transformação foi o alimentício, com o conceito do slow food, proposto por Carlo Petrini, em 1986. Após foi a vez do setor da moda incorporar esse conceito através do slow fashion, representando um movimento que estimula a consciência e a prática de sustentabilidade tanto nos consumidores quanto na indústria dabmoda (FLETCHER; GROSE, 2011).

Tendo como base esse plano de fundo, a proposta deste estudo consiste na apresentação dos conceitos de slow food e slow fashion, mostrando como ambos podem ser utilizados em conjunto para fomentar o turismo regional, sobretudo, a partir da potencialização do uso do mirtilo (vacciniummyrtillus) em ambos os setores: alimentos e moda, enfatizando o uso da fruta como corante natural.

A condução desse estudo ocorreu por meio de uma pesquisa experimental. Também foram utilizados como fonte de coleta de dados entrevista e visita in loco ao local selecionado para a pesquisa. Desse modo, o estudo foi organizado da seguinte forma: primeiramente são os conceitos de slow food e slow fashion. Em um segundo momento a matéria-prima mirtilo é caracterizada, bem como são apresentadas as suas potencialidades sob as óticas do slow food e do slow fashion, enfatizando o processo de tingimento com corantes naturais. Na sequência, no tópico da metodologia será abordado o estudo experimental, seguido pelos resultados e referências bibliográficas.

\section{FUNDAMENTAÇÃO TEÓRICA}

\subsection{Slow Food}

Nas últimas décadas muitas mudanças ocorreram relacionadas principalmente ao uso da tecnologia, que simplificou inúmeras atividades, aumentou a conexão 
entre pessoas e lugares e também o acesso à informação. Com isso, a rotina dos indivíduos ficou mais agitada, gerando, a longo prazo, um movimento contrário de desaceleração das atividades, dentre elas o ato de preparo e ingestão de alimentos (MIRANDA, 2014).

Com base nesse cenário, surgiu o Movimento slowfood, associação internacional sem fins lucrativos, fundada pelo escritor e gastrônomo italiano Carlo Petrini em 1986 na Cidade de Bra, na região do Piemonte na Itália. Outro motivo que incentivou a criação do movimento foi a abertura de uma filial da rede McDonalds na famosa Piazza Di Spagna, em Roma, na mesma época. Assim, em 9 de novembro de 1989 após a assinatura do Manisfesto slow food em Paris, o movimento foi criado oficialmente (WEBER, 2018).

O Manifesto slow food contestava os valores que embasavam a "vida veloz", além de exaltar as virtudes de uma vida lenta, baseada nos valores e nos prazeres dos sentidos e da sabedoria (GENTILLE, 2016).

Com o objetivo de promover a cultura gastronômica e ao mesmo tempo lutar por um desenvolvimento sustentável, o movimento prega a valorização das tradições da cozinha regional, tendo como prioridade os alimentos bons, limpos e justos, alimentos com um histórico artesanal e de qualidade que são gerados em um sistema que sabe respeitar o meio ambiente e também o produtor (WEBER, 2018).

O conceito de alimento bom, limpo e justo permeia a filosofia do movimento, sendo a base de ações e projetos. Esse conceito incorpora múltiplas instâncias:

A promoção do direito universal à alimentação saudável e de qualidade; a defesa da naturalidade dos produtos alimentares, das diversidades biológica e cultural ligadas a produção, preparo 
e consumo (bom); a promoção de formas produtivas em pequena escala (familiar, comunitária), ecologicamente corretas e capazes de respeitar o equilíbrio dos ciclos que ligam o sistema ambiente/homem/ matéria-prima (limpo); a denúncia das contradições globais entre fome e obesidade, carência e desperdício; respeito ao trabalhador e seu know-how, através da condenação de processos de produção e comercialização caracterizados por formas exploratórias (justo) (GENTILLE, 2016, p. 48).

Ademais, a sustentabilidade relacionada aos alimentos também está presente nos preceitos do movimento. Sob este aspecto, Petrini (apud GENTILLE, 2016, p. 48) assevera que "para julgar a sustentabilidade dos produtos alimentares, é preciso estar ciente das consequências ecológicas das ações que ocorrem na passagem do campo à mesa". Neste sentido, um produto é limpona medida em que é sustentável do ponto de vista ecológico, ou seja, é preciso avaliar as consequências de sua produção e processamento sobre o meio ambiente. Também fazem parte deste contexto a justiça social que se refere ao respeito para com os trabalhadores que produzem o alimento, e a sustentabilidade econômica, necessária para sua permanência no meio rural (GENTILLE, 2016).

Dentre as iniciativas promovidas pelo movimento slow food estão a Arca do Gosto, as Fortalezas, as Cidades Slow e os Conviviuns.

A Arca do Gosto é direcionada à catalogação de sabores esquecidos, documentando produtos gastronômicos que estão em risco de desaparecer. Após a catalogação criam-se as Fortalezas, que atuam em defesa das espécies alimentares ameaçadas por meio de projetos de apoio locais aos produtores. As Fortalezas são focadas em território específicos, podendo envolver um único produtor até milhares de agricultores familiares. Dentro do movimento também existem as Cidades Slow (Cittaslow), responsáveis por designar localidades providas 
de capital cultural e alimentar que possam aderir aos valores do movimento slow. As unidades associadas ao movimento são chamadas de Convivium. Estes aproximam produtores e consumidores, apoiam produtores por meio de campanhas de proteção de alimentos tradicionais, degustações e palestras, além de estimular chefs para o uso de alimentos regionais (CARVALHO, 2008).

Alinhado aos preceitos do movimento slowfood está o turismo gastronômico, que surge para priorizar as culturas regionais, e, juntamente com o turismo cultural, pode trazer elementos culturais regionais da alimentação e ofertá-los enquanto produtos turísticos locais, podendo assim, preservar as tradições alimentares de uma região e potencializar o desenvolvimento regional (WEINER, 2005).

Para Martins, Gurgel e Oliveira (2016, p. 232), o turismo gastronômico "é fundamental no processo de valorização do local, como uma resposta ao aumento da concorrência no contexto global. O interesse pelos produtos locais aponta não só para manutenção da diversidade do patrimônio, reforça a identidade cultural local e o orgulho da comunidade".

Associado ao turismo gastronômico, o slow food preserva a união do prazer por uma alimentação consciente e responsável, na qual a satisfação deve estar não somente no ato de preparar a comida, mas também no momento da degustação por parte do consumidor (De CARLI, 2012).

Nesse sentido, Peccini (2013), afirma que a gastronomia, na sua relação com o turismo, também envolve uma preocupação de como apresentar o espaço alimentar para receber os visitantes. Logo, entende-se todo o cuidado de preservação dos patrimônios gastronômicos, vistos como expressão cultural e a adequação dos espaços (bares, restaurantes e similares) a este enfoque, como um reflexo da contemporaneidade. 
O processo de turismo cultural e gastronômico, de fazer com que tradições culinárias se transformem em produtos turísticos pode gerar um novo significado para o alimento que foi apresentado, assim, um restaurante tradicional tem de servir comidas que lembram costumes, sabores e produtos regionais, tendo sua matéria-prima produzida por produtores locais de forma que concilie a atividade turística com a mão de obra local, a qual anteriormente poderia não ser ofertada, o que acaba ressignificando o prato o qual passa a ser uma representação social (PISARKI JUNIOR, 2017).

O mesmo ocorre quando o consumidor participa ou está consciente acerca do processo de plantio, colheita e preparação do alimento, construindo um vínculo afetivo por meio da experiência gerada (KRUCKEN, 2009).

De modo semelhante, existe no âmbito da moda um movimento análogo ao slow food, que busca a desaceleração do consumo e a valorização de produtos elaborados com materiais mais sustentáveis e de forma ética.

\subsection{Slow Fashion}

A abordagem lenta intervém como um processo revolucionário no mundo contemporâneo, pois incentiva a tomada de tempo para garantir uma produção de qualidade, para dar valor ao produto e contemplar a conexão com o meio ambiente. Neste sentido, O conceito slow fashion é usado para designar um processo de criação e produção dentro da mesma linha de pensamento do slow food: são peças desenvolvidas com ênfase no design, confeccionadas com matérias-primas selecionadas, com capricho e qualidade, para possibilitar um longo período de uso (De CARLI, 2012). 
Para Salcedo (2014), o slow fashion aborda um enfoque no qual designers, compradores, distribuidores e consumidores estão mais conscientes acerca do impacto das roupas sobre os seres humanos e ecossistemas. Neste sentido, a moda lenta não é um conceito baseado no tempo, e sim na qualidade que se relaciona ao tempo dedicado ao produto. Logo, a velocidade mais lenta e a ênfase na qualidade dão lugar a relações diferentes entre designer e produtor, o fabricante e as peças, a roupa e o consumidor.

A partir do momento em que o designer incentiva a utilização de processos de produção mais sustentáveis e a mudança de comportamento do consumidor no que se refere ao consumo e uso das peças, deixa-se de falar em design sustentável para passar a falar em design para a sustentabilidade (SALCEDO, 2014).

O slow fashion foi fundado pela inglesa Kate Fletcher, que se manifestou por meio de convicções semelhantes às do movimento slow food. O slow fashion aborda inúmeras das definições recentes encontradas na moda, como: eco, sustentável, verde, entre outros. E tem como propósito motivar a consciência ética e o consumo de produtos com uma qualidade superior, produzidos em pequena escala, seguindo de forma opositora à massificação da moda contemporânea. Esse movimento apresenta força no mercado de moda internacional e aos poucos começou a se apresentar no mercado brasileiro (MORI, 2016).

De Carli (2012) evidencia que produzir moda seguindo os princípios do slow fashion, não significa necessariamente manufaturar de forma lenta e em menor quantidade, mas elaborar e confeccionar melhores produtos, com maior valor agregado e com o máximo de durabilidade, tanto em termos de qualidade dos materiais, quanto na permanência do seu interesse e estética em várias estações.

Para Fletcher e Grose (2011), um dos principais aspectos do slow fashion, é o ciclo de vida do produto, que deve ser levado em conta do início ao fim do processo, incorporando as fases de pré-produção, produção, distribuição, uso e 
descarte. Como resultado, as peças produzidas neste sistema são criadas para serem duráveis, com modelagens atemporais e materiais não agressivos ao meio ambiente.

Fletcher e Grose (2011) sintetizaram as principais diferenças entre os sistemas de produção rápidos e lentos. Desse modo, o sistema de produção rápido (fast) apresenta como características: a produção em grande escala, a predominância de produtos com foco na globalização, o novo como condição de existência, a não consciência acerca dos impactos ambientais e o custo baseado em mão de obra e materiais. De modo diverso, o sistema de produção lento (slow) baseia-se em manufaturas de pequena e média escala, com produtos voltados ao global-local, ênfase na manutenção e atemporalidade das peças, consciência acerca dos impactos produzidos e predominância do preço real dos produtos, incorporando custos sociais e ecológicos.

Ademais, o slow fashion representa uma nova visão para estimular o consumo regional, o feito à mão e a exclusividade.

O movimento slow fashion engloba inúmeras ações dentro da indústria da moda, desde o cultivo e a utilização de fibras têxteis mais sustentáveis, passando pelo design, processos de produção do vestuário, beneficiamento têxtil e descarte (FLETCHER; GROSE, 2011).

No que tange aos beneficiamentos têxteis, grande parte do impacto ambiental gerado pela indústria do vestuário está relacionado aos processos de tingimento e estamparia, os quais utilizam corantes e materiais auxiliares poluentes que, de forma direta ou indireta, atingem os rios e a natureza (SALCEDO, 2014).

Dentro desse cenário, desponta como alternativa, a utilização de materiais naturais e biodegradáveis que possam ser incorporados nesses processos, valorizando além do resultado final, a forma de cultivo e extração dessas matérias-primas. 
Um exemplo a ser retratado é a utilização do mirtilo (vaccinium myrtillus) em processos de tingimentos têxteis, abordando tanto o ponto de vista do slow food, quanto o ponto de vista do slow fashion.

\subsection{As potencialidades do mirtilo (vaccinium myrtillus) sob as óticas do slow food e slow fashion}

\subsubsection{Mirtilo e slow food}

O mirtilo (Imagem 1) é uma fruta do gênero Vaccinium. Uma planta nativa da América do Norte, desde o Sul dos Estados Unidos até o Leste do Canadá da família botânica Ericaceae. Foi introduzido no Brasil pela Embrapa na década de 1980, na região Sul, onde os invernos rigorosos proporcionaram boa adaptação da planta, principalmente nas regiões de maior altitude. Nos Estados Unidos e na maior parte do mundo é conhecido como Blueberry, e na Argentina como Arándano (EMPÓRIO DO MIRTILO, 2019).

Imagem 1 - Plantação de Mirtilos
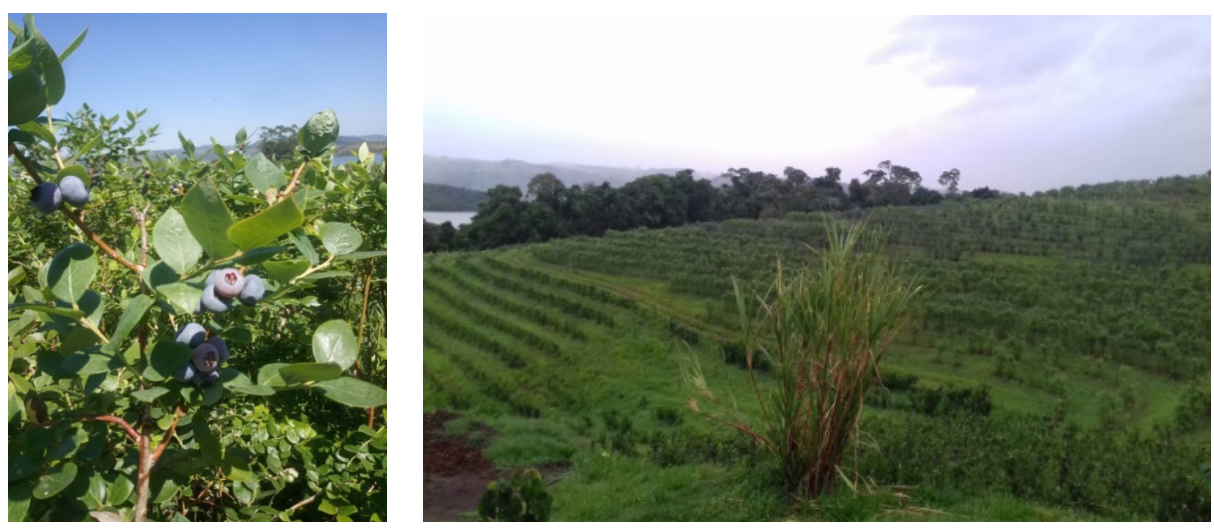

Fonte: Empório do Mirtilo (2019). 
O mirtilo é reconhecido por conta de suas propriedades nutraceuticas, possui uma grande concentração de antioxidantes e anti-inflamatórios naturais. Considerada também uma planta medicinal, do mirtilo podem ser consumidos não só os frutos, mas as flores, folhas e raízes. Os frutos são consumidos in natura e usados em sucos, geleias e iogurtes, já as folhas podem ser consumidas na forma de salada ou chá (EMPÓRIO DO MIRTILO, 2019).

O mirtilo é um arbusto cuja vida produtiva é de quinze anos. As raízes são delicadas e superficiais, e a parte superior da planta renova-se anualmente. Durante o inverno, os galhos novos perdem as folhas, brotando novamente a partir do mês de agosto. Esses gomos são os que produzem as frutas durante o período primavera/verão. O solo deve ser ácido, ter uma alta concentração de matéria orgânica e o relevo deve ser preferentemente, plano. Para obter uma boa frutificação, ela precisa entre 200 e 1.000 horas de frio, dependendo da variedade. É bastante exigente em água, sendo fundamental a implantação de sistemas de irrigação. Já no primeiro ano há uma pequena produção de fruta, mas só depois do quarto ano a planta produz plenamente. A fruta está madura quando sua cor se torna um azul mais intenso. A colheita é manual e se realiza com extremo cuidado. Depois acontece a limpeza, a seleção, a embalagem e o armazenamento refrigerado (EMPÓRIO DO MIRTILO, 2019).

Na região Oeste de Santa Catarina, encontra-se o município de Itá, no qual localiza-se o Empório do Mirtilo responsável pelo cultivo e comercialização de produtos elaborados a partir dessa fruta.

Conforme informações coletadas no site institucional da empresa², o Empório do Mirtilo surgiu para inovar a forma de comercialização de frutas finas 
(mirtilo, amora, framboesa, morango e phisalys). Seus produtos são processados de forma artesanal e industrial, de maneira eficiente, através de seus parceiros. Está alicerçada na empresa Itaberry Frutas Finas, que atua na produção e plantio de frutas no município de Itá.

Junto ao cultivo e comercialização da fruta, o Empório do Mirtilo possui o sistema colhe e pague, no qual os consumidores participam do processo de colheita da fruta e posterior consumo. Conforme Neyhaus $(2019)^{3}$, sócio do empreendimento, o sistema colhe e pague do mirtilo surgiu a partir de uma consultoria da empresa de desenvolvimento turístico e ambiental, Grupo Eco\&Eco, e assim começou a comercialização. Nas palavras de Neyhaus (2019),

[...] Por se tratar de uma cultura relativamente nova no Brasil, a ideia era proporcionar uma experiência turística única aos visitantes, mas tudo isso foi pensado de forma que não agredisse o meio ambiente, sempre visamos ter como base a sustentabilidade, por isso na propriedade onde tem a plantação de mirtilo existem 180 placas solares que geram energia para ser utilizada no container que mantem a fruta resfriada/congelada.

O processo de colhe e pague pode se associar ao movimento slow food na medida em que ocorre a manipulação de uma refeição saudável com maior apreciação do alimento, juntamente com a valorização da produção regional, do produtor e do meio ambiente.

[3] NEYHAUS, Felipe. Entrevista referente ao modo de funcionamento do sistema colhe e pague do mirtilo. Itá, 22 out. 2019. Entrevista. 
A colheita do mirtilo acontece de outubro a dezembro, e o fruto pode ser utilizado para diversos fins, como sucos, geleias, licores, podendo ser produzidos cosméticos e também erva-mate, farinhas e desidratados. Esses produtos são comercializados através de um site que funciona como um e-commerce e também, através de vendedores que trabalham principalmente em Santa Catarina, sendo a cidade de Chapecó o maior mercado.

A divulgação ocorre por meio das redes sociais, de alguns eventos e por meio do tradicional boca-a-boca. A comercialização do mirtilo acontece in natura o qual o $\mathrm{Kg}$ é vendido por um valor de $\mathrm{R} \$ 60,00$ e o congelado a um valor de $R \$ 30,00$, contudo, o produto in natura está livre da tributação, enquanto o processado sofre com uma tributação de 17\% de ICMS (NEYHAUS, 2019).

Para Neyhaus (2019), o Empório do Mirtilo adotou o sistema colhe e pague por acreditar no potencial dessa fruta e acreditar que a diversificação na utilização desta pode trazer bons resultados, posto que o mirtilo é uma fruta que possui uma versatilidade muito grande, sendo inclusive utilizado pela empresa na produção de cosméticos. Uma nova alternativa de utilização associada à moda seria a produção de ecobags tingidas com a própria fruta, sendo que atualmente são utilizadas cestas de vime para a colheita. Para Neyhaus (2019), a produção de ecobags e seu tingimento com o mirtilo consistiria em mais uma experiência que o turista poderia vivenciar.

\subsubsection{Mirtilo e slow fashion}

O conceito de slow fashion traz consigo a ideia de aproximação entre empresa e consumidor final, objetivando apresentar produtos exclusivos com qualidade única, criando assim uma relação afetiva a fim de conquistar o cliente e sua fidelidade (CIETTA, 2012). 
Neste sentido, sob o viés do slow fashion, o processo de tingimento têxtil com corantes naturais, no caso a fruta mirtilo, poderia ser utilizado pela empresa Empório do Mirtilo como uma forma de aproximação entre esta e seus consumidores, enfatizando ainda mais a experiência do sistema colhe e pague. Além disso, podem ser destacadas as múltiplas utilidades da fruta, que vão desde o uso para fins de alimentação, passando pela cosmética, até a utilização na indústria da moda, especificamente, como corante natural.

\subsubsection{0 processo de tingimento têxtil com corantes naturais}

Os corantes naturais são encontrados com mais facilidade e maior diversidade principalmente nos vegetais (plantas, árvores e líquens), mas também podem ser encontrados em animais como nos insetos e moluscos (FERREIRA, 2005).

Os corantes naturais são formados por pigmentos que podem ser originários do meio orgânico (animais e vegetais) ou inorgânico (mineral) e quando fluidos em um líquido, se transformam num corante ou tintura. Há, porém, uma diferença essencial entre eles: o pigmento é insolúvel em seu solvente, enquanto a tintura é solúvel. Por isso, são classificados em: corantes minerais (carvão, hematita, malauita, dentre outros), corantes vegetais (plantas, caules, folhas, rizomas e raízes) e corantes animais (proveniente de moluscos, insetos e caracóis marinhos) (TRINCA, 2017).

De acordo com Ferreira (2005), devem-se levar em conta alguns procedimentos durante a colheita dos materiais a serem utilizados em processos de tingimento natural. Assim, a coleta de folhas, flores, sementes e frutos devem ser realizadas antes do período de floração, onde a concentração de corante é maior. A retirada de cascas deve ser realizada em faixas no sentido longitudinal, para não machucar ou tirar a vida da planta. Geralmente a coleta de raízes leva à morte das plantas, logo, para uma colheita consciente é necessário que a cada raiz coletada, plantem-se duas novas. 
Antes do tingimento, as fibras de origem vegetal como algodão e linho, devem ser preparadas por meio de um "pré-mordente", uma solução rica em ácido tânico, mais conhecido como tanino. É uma substância de coloração amarela ou marrom, extraída da seiva, casca e folhas de muitas plantas como a goiabeira e a língua-de-vaca. Os tecidos compostos por fibras vegetais não possuem uma carga influente, nem positiva (prótons), nem negativa (elétrons), a maioria dos corantes naturais são ricos em elétrons e os taninos são fonte de prótons. Por esta razão é importante que o substrato seja preparado e carregado com cargas positivas pelo banho, assim, a ligação entre o corante e a fibra torna-se mais eficaz. Realizando corretamente este procedimento, podem se obter cores intensas e duradouras nas fibras vegetais (FERREIRA, 2005).

Outro fator que influencia na intensidade das cores são os tipos de recipientes utilizados para o tingimento, a lata quando se encontra oxidada escurece todas as cores, já a panela de barro composta pelos minerais do barro têm influência na cor resultante, diferente da panela de ferro que favorece cores escuras, contudo, se a intenção é obter como resultado cores mais vivas o ideal é utilizar uma panela de alumínio, porém, pode ocorrer uma leve alteração na tonalidade da cor. Ao utilizar o tacho de cobre, as cores ficarão ainda mais vivas, principalmente do rosa ao tijolo passando pelo vermelho, as panelas ágata e de inox não influenciam no resultado das cores, ficando em sua maioria vivas (SILVA, 2016).

Ferreira (2005) cita três etapas pelas quais o tingimento natural é realizado:

1. Seleção da matéria corante;

2. Extração do corante por método de fervura, precipitação ou fermentação, tornando o corante, antes fixado, novamente em solúvel ou flutuante;

3. Preparação do banho de tingimento, inserção dos fios, fibras ou tecidos, dando assim um novo corpo à cor. 
De acordo com Salem (2010), todo tingimento deve atender às seguintes características:

a) Afinidade: o corante passa a ser parte integrante da fibra;

b) Igualização: a cor aplicada deve ser uniforme em toda a extensão do material têxtil;

c) Resistência: a cor do material deve resistir aos agentes desencadeadores de desgaste que irão atuar sobre o artigo.

d) Economia: o tingimento do material têxtil deverá ter características assinaladas nos itens (a), (b) e (c), sem, contudo, ultrapassar as quantidades estritamente necessárias de corantes, produtos auxiliares e tempo de realização.

\section{METODOLOGIA}

A condução deste estudo ocorreu por meio de uma pesquisa experimental.

Foram utilizados como instrumentos de coleta de dados a entrevista e a visita in loco ao local selecionado para a pesquisa, a qual contribuiu para que fosse possível aprofundar o estudo (GIL, 2008),

A entrevista foi realizada entre os dias 21 e 22 de outubro de 2019 com Felipe Neyhaus, um dos sócios da empresa Empório do Mirtilo. A entrevista foi realizada por meio de um questionário composto por 14 questões abertas, enviado ao respondente via e-mail. Antes da aplicação o questionário foi validado por dois avaliadores da área de Alimentos do Instituto Federal do Rio Grande do Sul, campus Erechim. 
No dia 27 de outubro foi realizada uma visita in loco na empresa a fim de coletar a assinatura do respondente junto ao TCLE (Termo de Consentimento Livre e Esclarecido) e também para conhecer as instalações e o pomar de mirtilos. $\mathrm{Na}$ ocasião, o sócio entrevistado fez uma doação de aproximadamente $1 \mathrm{~kg}$ da fruta in natura para que pudesse ser utilizada na etapa experimental da pesquisa.

Em seguida foi realizada a pesquisa experimental, a qual baseia-se na tentativa e erro, realizada por meio de testes e experimentos. Caracterizada por manipular de modo direto os elementos que serão utilizados para o estudo, de forma geral a pesquisa experimental é comporta pela compreensão do modo e causa a qual o fenômeno é produzido (TYBEL, 2017).

A pesquisa experimental testou o tingimento com a fruta mirtilo, e obedeceu ao seguinte protocolo definido por Ferreira (2005):

1. Seleção da matéria corante;

2. Extração do corante por método de fervura;

3. Preparação do banho de tingimento e inserção do tecido;

Também foi utilizada a receita base para tingimento com casca de cebola definida por Ferreira (2005).

Foram realizados dois experimentos (a) e (b) com a matéria-prima sob duas formas diferentes:

a) Utilizando a casca da fruta;

b) Utilizando a fruta em estado de decomposição;

Seguindo o protocolo de Ferreira (2005), para o experimento (a) a primeira etapa consistiu na seleção da matéria-prima. Neste caso, as cascas de mirtilo. Foram utilizadas 100 gramas de cascas. 
A segunda etapa consistiu na extração do corante por meio de fervura. Assim, foram empregadas as 100 gramas de casca in natura em uma quantidade de 3 litros de água. Durante o procedimento, foi utilizado um recipiente de alumínio, que, de acordo com Silva (2016) é ideal para gerar cores vivas. A matéria-prima foi colocada em alta temperatura até atingir o estado de ebulição, permanecendo neste estado durante 30 minutos. Em seguida, a matéria-prima foi retirada (coada), permanecendo no recipiente um líquido de cor arroxeada.

A terceira etapa consistiu na preparação do banho de tingimento e inserção do tecido. Antes do banho de tingimento foi preparado um mordente para a melhor fixação do corante. O mordente utilizado foi o alúmen (sal branco). Assim, o sal (50 gramas) foi misturado à 3 litros de água. Em seguida o tecido foi submerso nesta substância até atingir o ponto de ebulição, permanecendo nela por 30 minutos. Foi utilizado o tecido linho de composição 100\% linho no tamanho 15×15 centímetros. Após o banho no mordente, o tecido foi inserido no banho de tingimento, onde permaneceu sob fervura durante 30 minutos.

Para finalizar, o tecido foi lavado em água corrente para retirar o excesso de corante. A imagem 2 demostra o processo referente ao experimento feito somente com a casca do mirtilo (a).

Imagem 2 - Experimento (a).

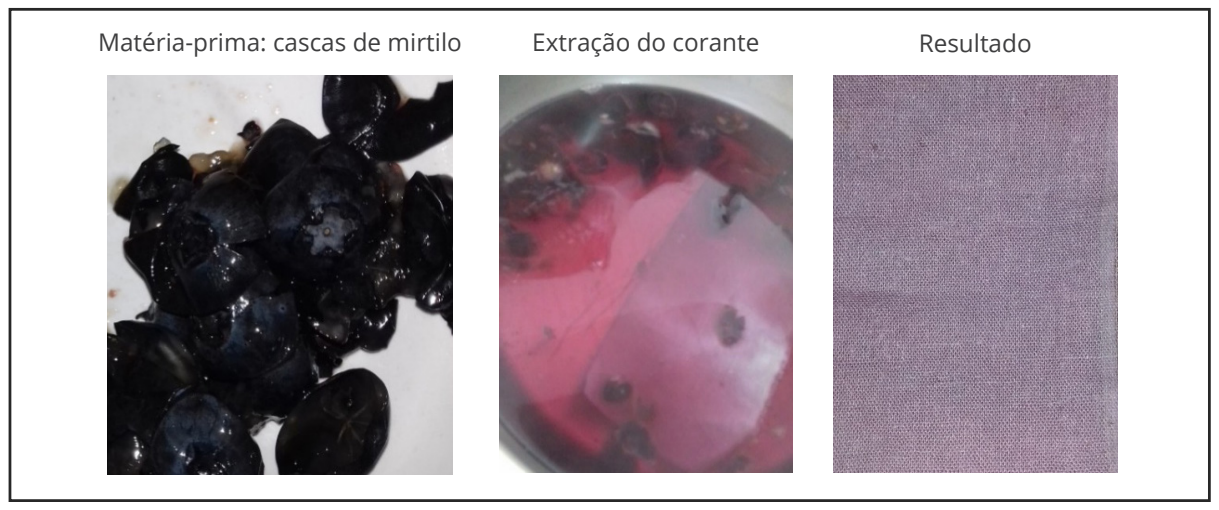

Fonte: As autoras (2019). 
Seguindo o protocolo de Ferreira (2005), para o experimento (b), a primeira etapa consistiu na seleção da matéria-prima. Neste caso, o fruto em estado de decomposição. Foram utilizadas 100 gramas de frutos.

A segunda etapa consistiu na extração do corante por meio de fervura. Assim, foram utilizadas as 100 gramas do fruto em decomposição em uma quantidade de 3 litros de água. Durante o procedimento, foi utilizado um recipiente de alumínio, que, de acordo com Silva (2016) é ideal para atingir cores vivas. A matéria-prima foi colocada em alta temperatura até atingir o estado de ebulição, permanecendo neste estado durante 30 minutos. Em seguida a matéria-prima foi retirada (coada), permanecendo no recipiente um líquido de cor arroxeada escura.

A terceira etapa consistiu na preparação do banho de tingimento e inserção do tecido. Antes do banho de tingimento foi preparado um mordente para a melhor fixação do corante. O mordente utilizado foi o alúmen (sal branco). Assim, o sal (50 gramas) foi misturado à 3 litros de água. Em seguida o tecido foi submerso nesta substância até atingir o ponto de ebulição, permanecendo nela por 30 minutos. Foi utilizado o tecido linho de composição 100\% linho no tamanho 15×15 centímetros. Após o banho no mordente, o tecido foi inserido no banho de tingimento, onde permaneceu sob fervura durante 30 minutos.

Para finalizar o tecido foi lavado em água corrente para retirar o excesso de corante. A imagem 3 do tingimento com o mirtilo em decomposição demostra o processo referente ao experimento (b). 
Imagem 3 - Experimento (b).

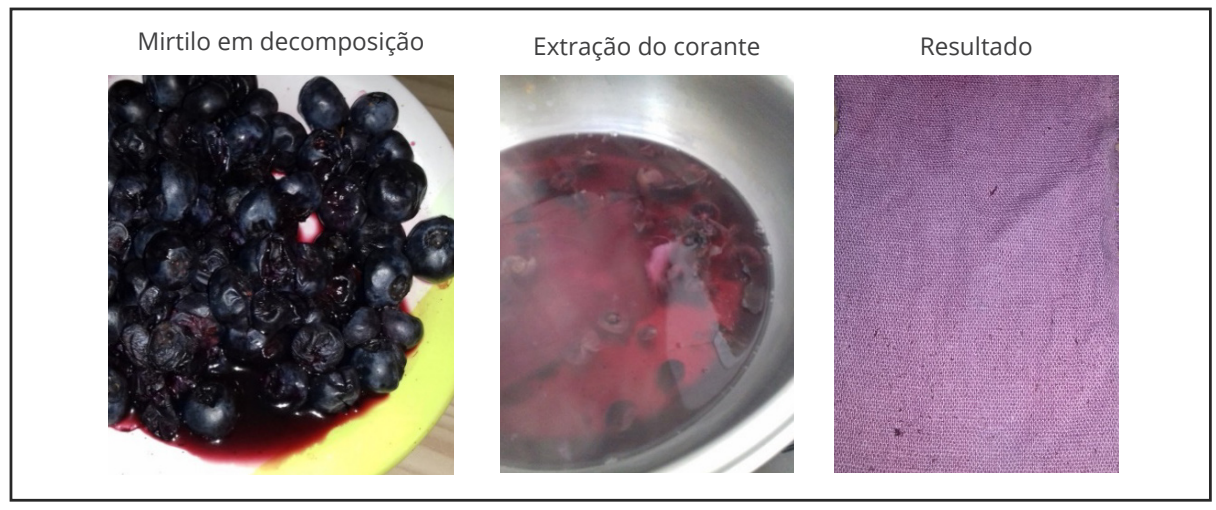

Fonte: As autoras (2019).

Após a realização dos experimentos (a) e (b) foi tingida a quantidade de 1 metro do mesmo tecido (linho 100\% linho), utilizando as cascas de mirtilo. Foram utilizadas 300 gramas de casca e 6 litros de água. A temperatura e o tempo do processo foram os mesmos do experimento (a).

O objetivo deste procedimento foi tingir o tecido para utilizá-lo posteriormente na confecção de uma ecobag que poderia ser utilizada durante o processo de colhe e pague do mirtilo. Desse modo, a replicação do experimento (a) em uma quantidade de tecido maior, possibilitaria a análise visual da igualização do corante.

Assim, após a finalização do tingimento e secagem do tecido, procedeu-se à confecção da ecobag. Esta foi desenvolvida a partir da adaptação de um molde já existente, que foi cortado no tecido tinto. Em seguida, as partes cortadas foram unidas por costura reta. 
Este processo pode ser visualizado na imagem 4, tingimento e confecção da ecobag.

Imagem 4 - Processo de confecção da ecobag.

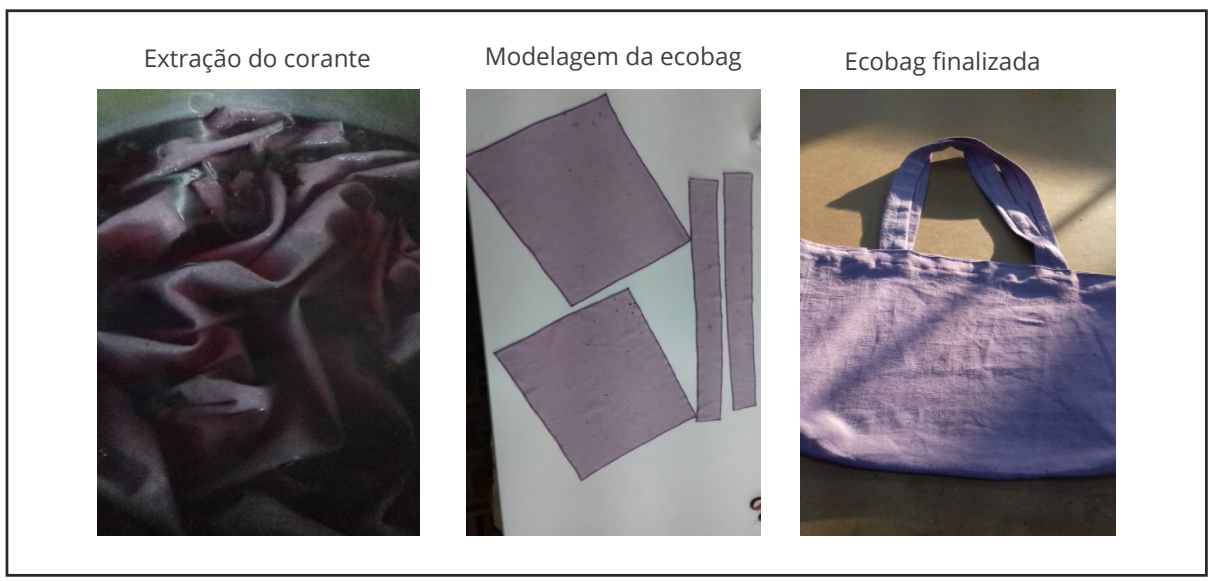

Fonte: As autoras (2019).

\section{RESULTADOS}

Para a aferição dos resultados, foram analisados os efeitos dos experimentos (a) e (b) levando em conta as características citadas por Salem (2010) em relação aos tingimentos: afinidade, igualização, resistência e economia.

Assim, em relação ao resultado do experimento (a) constatou-se que a amostra obteve índices satisfatórios no que tange às características: afinidade, igualização e resistência. Desse modo, o corante extraído do mirtilo passou a fazer parte da fibra, bem como a cor adquirida manteve-se uniforme em toda a extensão do material têxtil. Além disso, a cor resistiu ao banho em água corrente. Contudo, em relação ao fator economia, o valor comercial do mirtilo é um tanto elevado, o 
que seria responsável pela maior parte dos custos de uma produção ampliada, mesmo que em nível artesanal.

Quanto ao experimento (b), constatou-se que a amostra obteve índices satisfatórios em relação à todas as características: afinidade, igualização, resistência e economia. Em relação ao fator economia, o experimento (b) mostrou ser mais viável, uma vez que são utilizadas as frutas em estado de composição, aproveitando-a por completo.

Em seguida, os resultados dos experimentos (a) e (b) foram comparados entre si, conforme a imagem 5.

Imagem 5 - Resultado dos experimentos (a) e (b).

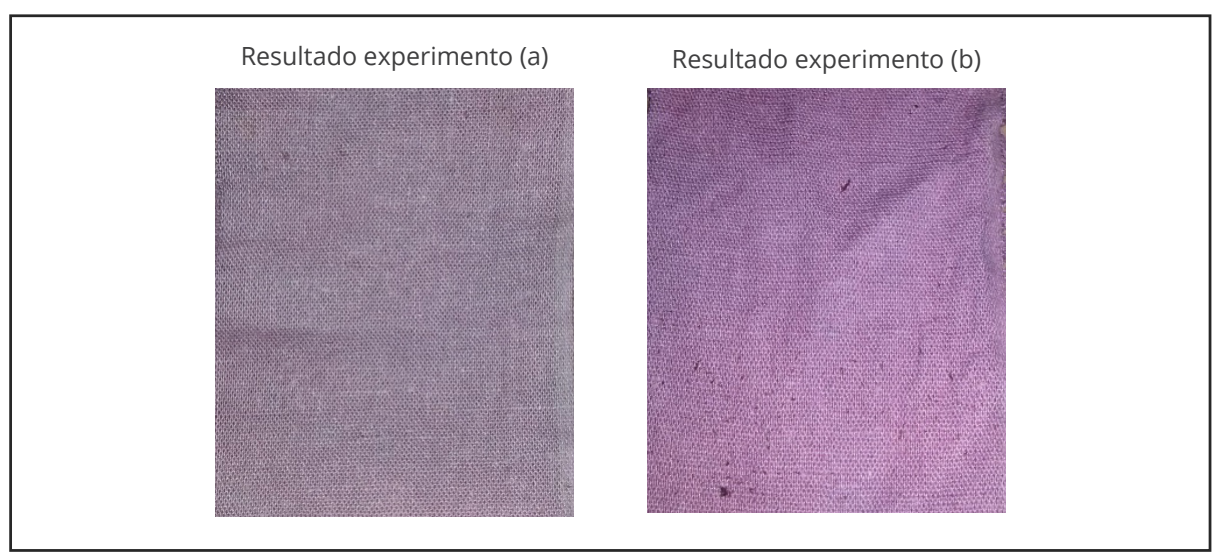

Fonte: As autoras (2019).

Por meio da análise visual, observou-se que a amostra resultante do experimento (b) possui uma cor mais vibrante, esteticamente superior em relação ao experimento (a), que obteve uma cor mais apagada. Entretanto, ambas as tonalidades podem ser utilizadas comercialmente. 
Em relação ao desenvolvimento da ecobag, infere-se que o tecido utilizado poderia ter uma gramatura mais elevada, o que garantiria uma resistência maior ao produto. Entretanto, como os experimentos foram realizados com amostras de linho 100\% linho, optou-se por manter o mesmo material, para não alterar as características obtidas.

\section{CONSIDERAÇÕES FINAIS}

O propósito desta pesquisa foi demonstrar como dois movimentos de áreas diferentes como alimentos e moda podem andar juntos e proporcionar experiências únicas, levando em consideração a preservação ambiental e a sustentabilidade.

Ao longo da pesquisa foi exposto o conceito do slow food, criado por Carlo Petrini com o intuito de destacar a cultura gastronômica local e também defender um desenvolvimento mais sustentável, privilegiando produtos com um histórico artesanal, valorizando o produtor e protegendo o meio ambiente.

Além disso, o movimento slow food não ficou limitado à área de alimentos, tampouco ficou restrito entre as fronteiras nacionais e europeias que denotam sua origem. Ao contrário, o slow food expandiu suas ações, incorporando novas demandas e áreas de atuação, dentre elas, a moda. Neste sentido, o movimento slow fashion destaca a sustentabilidade nas etapas do desenvolvimento de produtos, que vão desde a produção de fibras até o consumo e descarte. O slow fashion foi fundado por Kate Fletcher, objetivando além da incorporação de práticas mais sustentáveis durante os processos de produção de vestuário, motivar os consumidores a adquirirem produtos com mais qualidade e que são produzidos em menor escala, valorizando a mão de obra e a procedência destes. 
As potencialidades do mirtilo... Fashion MESACASA, A.; SZABAT, C. N.

Opropósito desta pesquisa foidemonstrar como do is movimentos de áreas diferentes como alimentos e moda podem andar juntos e proporcionar experiências únicas, levando em consideração a preservação ambiental e a sustentabilidade. 
Não obstante, buscando a integração de ambos os movimentos estudados, foi utilizado o tingimento com corantes naturais, especificamente o mirtilo como ponte de ligação.

Ao longo do estudo também foi exposto o sistema colhe e pague implantado na empresa Empório do Mirtilo no município de Itá - SC, que traz com essa experiência um fomento ao turismo regional.

Em relação aos experimentos realizados (a) e (b) conclui-se que ambos podem ser utilizados como experiências de consumo sustentável sob a ótica do slow fashion, principalmente no que tange à biodegrabilidade da fibra natural utilizada (linho) e à matéria-prima corante (mirtilo).

A respeito da ecobag confeccionada, caso esta fosse incorporada ao sistema colhe e pague, poderia ser destacada a origem do produto e o processo de tingimento nele empregado, valorizando ainda mais o fruto mirtilo. Neste caso, a ecobag poderia ser oferecida aos consumidores para auxiliar no momento da colheita, ou o processo de tingimento artesanal poderia ser realizado durante o trajeto percorrido na colheita, valorizando a transparência e sustentabilidade do processo.

Como sugestão para futuros trabalhos, poderia ser desenvolvido um estudo específico enfatizando o design para a ecobag, uma vez que a presente pesquisa não objetivou tal resultado.

Concluindo, destaca-se que o processo de tingimento artesanal com corante natural explorado neste estudo possui potencial para agregar maior valor ao sistema colhe e pague do mirtilo, evidenciando aspectos relevantes de ambos os movimentos: slow food e slow fashion, que podem ser integrados em uma experiência de consumo relevante para o turismo regional. 
O processo de tingimento artesanal com corante natural explorado neste estudo possui potencial para agregar maior valor ao sistema colhe e pague do mirtilo, evidenciando aspectos relevantes de ambos os movimentos: slow food e slow fashion, que podem ser integrados em uma experiência de consumo relevante para o turismo regional. 
Projética, Londrina, v. 12, n. 2, p. 317-347, agosto 2021

\section{REFERÊNCIAS}

1. CARVALHO, Isabel Cristina Moura. Slow food e a educação do gosto: um movimento social sem pressa. Revista Prâksis, Novo Hamburgo, v. 1, p. 101107, jan./jun. 2008.

2. CIETTA, Enrico. A evolução do fast-fashion. São Paulo. Estação das Letras e Cores, 2012.

3. De CARLI, Ane Mery Sehbe. Moda, sustentabilidade e emergências. Caxias do Sul: Educs, 2012.

4. EMPÓRIO DO MIRTILO. Nossa história. Disponível em: https:// emporiodomirtilo.com.br/sobre-nos/. Acesso em: 20 set. 2019.

5. FERREIRA, Eber Lopes. Tingimento vegetal: teoria e prática sobre tingimento com corantes vegetais. Brasília, DF: Ministério do Meio Ambiente, 2005.

6. FLETCHER, Kate; GROSE, Lynda. Moda e sustentabilidade: design para a mudança. São Paulo: Senac, 2011.

7. GENTILLE, Chiara. Slow Food na Itália e no Brasil. história, projetos e processos de valorização dos recursos locais. 2016. Tese (Doutorado em Desenvolvimento Sustentável) - Centro de Desenvolvimento Sustentável, Universidade de Brasília, Brasília, 2016.

8. GIL, Antônio Carlos. Métodos e técnicas de pesquisa social. 6. ed. São Paulo: Atlas, 2008.

9. KRUCKEN, Lia. Design e território: valorização de identidades e produtos locais. São Paulo: Studio Nobel, 2009. 
As potencialidades do mirtilo... Fashion MESACASA, A.; SZABAT, C. N.

10. MARTINS, Uiara Maria Oliveira; GURGEL, Lorena Ibiapina ; OLIVEIRA, José Clerton de. Experiências com a gastronomia local: um estudo de caso sobre movimento Slow Food e o turismo gastronômico na cidade de Recife, Brasil. PAsos - Revista de Turismo y Patrimonio Cultural, La Laguna, v. 14, n. 1, p. 229-241, 2016.

11. MIRANDA, Bruna. Slowlife: desacelerar o ritmo. 2014. Disponível em: http:// reviewslowliving.com.br/2014/05/05/slow-life-desacelerar-o-ritmo/. Acesso em: 22 set. 2019.

12. MORI, Natalia Tinoco. Slow Fashion: conscientização do consumo de moda no Brasil. 2016. Monografia (Especialização em Estética e Gestão de Moda) Escola de Comunicações e Artes, Universidade de São Paulo, São Paulo, 2016. Disponível em: http://www2.eca.usp.br/moda/monografias/NATALIA\%20 MORI-USP.pdf. Acesso em: 22 ago. 2019.

13. NEYHAUS, Felipe. Entrevista referente ao modo de funcionamento do sistema colhe e pague do mirtilo. Itá, 22 out. 2019.

14. PISARSKI JUNIOR, Marcos Roberto; SOUZA, Silvana do Rocio de; PANZARINI, Yanca Theresia Peters. $O$ movimento slow food e suas interfaces com - turismo: uma breve análise no Centro Histórico de Curitiba/PR, 2017. In: SEMANA PARANAENSE DE TURISMO DA UFPR, 24., 2017, Curitiba. Anais [...]. Curitiba: UFPR, 2017, p. 1-20. Disponível em: https://eventos.ufpr.br/ sepatur/SEPATUR/paper/download/943/280. Acesso em: 24 set. 2019.

15. PECCINI, Rosana. A gastronomia e o turismo. Revista Rosa dos Ventos, Caxias do Sul, v. 5, n. 2, p. 206-217, 2013. 
Projética, Londrina, v. 12, n. 2, p. 317-347, agosto 2021

16. SALCEDO, Elena. Moda ética para um futuro sustentável. Barcelona: Editora Gustavo Gili, 2014.

17. SALEM, Vidal. Tingimento têxtil. São Paulo: Edgard Blücher, 2010.

18. SANTOS, Aguinaldo. Sistema produto + serviço sustentável: fundamentos. Curitiba: Insight, 2018.

19. SILVA, Izabelle Todesquini. Tingimento natural em produtos de moda: alternativas para torná-lo mais eficaz. In: CONGRESSO BRASILEIRO DE INICIAÇÃO CIENTÍFICA EM DESIGN DE MODA, 3.; COLÓQUIO DE MODA, 12; EDIÇÃO INTERNACIONAL, 9., 2016, [Curitiba]. Anais [...]. [Curitiba]: UTFPr, 2016. p. 1-4. Disponível em: http://www.coloquiomoda.com.br/anais/ Coloquio\%20de\%20Moda\%20-\%202016/POSTER/PO-08-Sustentabilidade/ PO-08-TINGIMENTO-NATURAL-EM-PRODUTOS-DE-MODA-ALTERNATIVASPARA-TORNA-LO-MAIS-EFICAZ.pdf. Acesso em: 25 ago. 2019.

20. TRINCA, Fabíola. Tingimento natural: novos desafios e ações sustentáveis. Rio de Janeiro, 2017. In: MAROTTO, Isabela (coord.). + Sustentabilidade às marcas de moda: reflexões e indicadores. Rio de Janeiro: [s. n.], 2017. cap. 9, p. 125-154. Disponível em: http://porfavormenoslixo.com.br/wp-content/ uploads/2018/01/LIVRO-SUSTENTABILIDADE-\%C3\%80S-MARCAS-DE-MODA. pdf. Acesso em: 24 set. 2019.

21. TYBEL, Douglas. o que é pesquisa experimental? 2017. Disponível em: https://guiadamonografia.com.br/pesquisa-experimental/. Acesso em: 12 nov. 2019. 
As potencialidades do mirtilo... Fashion MESACASA, A.; SZABAT, C. N.

22. WEBER, Mariana. Carlo Petrini, criador do slow food: Falar só de receitas é pornografia alimentar. 2018. Disponível em: https://ocadernodereceitas. com.br/2018/04/26/carlo-petrini-criador-do-slow-food-falar-so-de-receitase-pornografia-alimentar/. Acesso em: 25 set. 2019

23. WEINER, Sarah. 0 manual slow food. Tradução de Loreta Sardo. 2. ed. Cuneo: Slow Food, 2005. 